\title{
Posture Dependency of 3D-Body Scanning Data for a Virtual Product Development Process in Apparel Industry
}

\author{
Michael ERNST ${ }^{\star 1,2}$, Ute DETERING-KOLL ${ }^{* 1}$ \\ ${ }^{1}$ Niederrhein University of Applied Sciences, Germany; \\ ${ }^{2}$ Cape Peninsula University of Applied Sciences, South Africa
}

http://dx.doi.org/10.15221/14.248

\begin{abstract}
Nowadays the product development process in apparel industry is mainly influenced by the customerthe so called target group. Companies spending mass of time and effort to analyze the target marketsnational and international- to gain valuable information assisting them in building up company dependent body measurement charts, final measurement charts for their products and necessarily grading tables for the size range offered.

Most companies are working with fitting models- representing more or less the "vision of the brand" and- if well selected- the basic size of their measurement charts and hopefully the customer.

Unfortunately in most cases the fitting is done- due to time and costs- with one model and leads to the fact of a tailor made fitting process for this person with a non-defined physical and mental state on this day [4].

Virtual Product Development is a powerful tool to overcome these barriers. By using statistical avatars representing the target group aimed for, and scanatars from various fitting models it is possible to check the sizing and to screen the fit of a product on slightly different bodies and postures of the same size in a quite short time. However it is not negligible to control the body scanning process in detail to get really the information wanted.
\end{abstract}

Keywords: 3D body scanning; posture and pose; sizing and fit, 3D simulation, virtual product development

\section{Introduction}

Sizing and Fit is the most critical part of a successful product development in garment industry [1]. First of all realistic body measurement charts must be available matching to the focused target group. The pattern is based on different construction systems with specified construction rules, chosen ease to achieve a certain fit. Most companies are working from the beginning on with finished measurement charts according to the measurements taken in a quality check of prototyping samples, sales-mansamples or production. Unfortunately these measurements cannot contain detailed information about the three dimensional aspects of a garment- e.g. bust dart content.

Body dimensions and measurements are changing all the time and no steady state can be achieved $[5,6]$.

This becomes critical if the changes reach or exceed the grading values. Thus first of all the generation of measurements- manually taken or with scanning technology- is absolutely difficult and requires expertise in the field to get representative measurements.

The measurements and the scans obtained are only representing a "snap-shot" of the reality.

Generating scanatars from single snap-shots bears the risk of creating unrealistic fitting conditions.

In this paper the most important influences on body scanning technology for the garment industry are discussed and awareness for the meaning of controlled scanning conditions should be created.

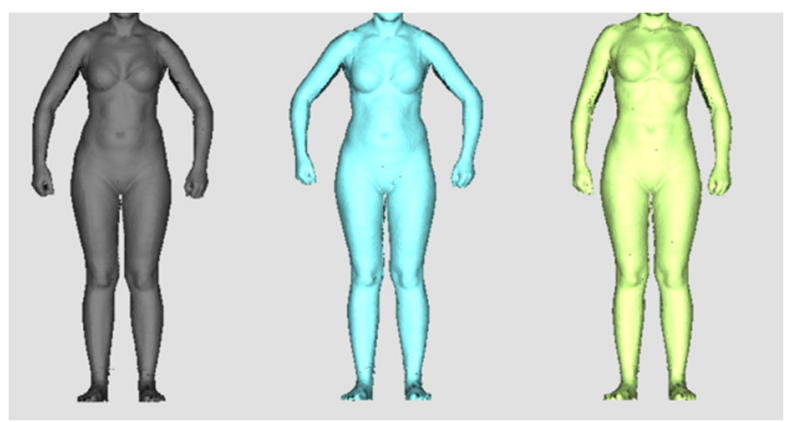

Fig.1: Body scanning- different breathing conditions and slightly different arm position 


\section{3D body scanning parameters}

The parameters for 3D body scanning are given by the scanning technology on one side and the scanning procedure on the other side. Apart from different scanning technologies, calibration aspects and flexibility in traveling the scanning subject itself is the most important part of the process.

Body scanning technology for apparel industry is strongly related to design aspects and linked directly to sizing and fit in a technical product development process $[9,10]$. Also national sizing surveysscanning thousands of subjects with the objective of getting data not only for fashion industry- are done with restrictive parameters to control the process and to generate reliable data [7].

Virtual Fittings in companies can be done by adaptation of given parametric mannequins to in-house measurements, working with well-prepared statistical avatars or individual avatars of fitting models.

Especially the last one offers the possibility of checking fit on well-known bodies- but time and cost saving - in 3D fittings.

For all these scanning processes the moment of scanning freezes a 3D picture of a person and represents only a snap-shot- more or less reflecting the reality. Regarding bodies of human beings in detail show motion and thereby change all the time. The parameters are therefore given by the subject itself and have to be controlled compulsory. Because of the individual bodies and individual behavior chest motion during breathing, posture and position is also an individual matter but possible to control instead of physical and mental aspects- e.g. personal well-being of the day.

Although the process of generating scanatars can become tricky for special target groups, e.g. plus size female- and the scanning position has to be changed to get proper data, these scanatars are equivalent to material characteristics and the pattern itself in a 3D simulation and contribute significantly to its success [3].

Fig. 2 shows the fundamentals of chest motion during breathing and the most important muscles for body balance- directly influencing the results obtained from scanning.

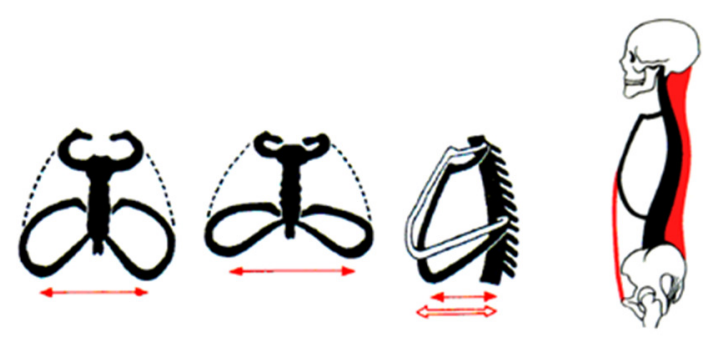

Fig. 2: Fundamentals of chest motion during breathing and most important muscles for body balance [8]

\section{Research methodology}

The following chapters include the information about the sample group and in detail the scanning investigations carried out for verifying the importance of a well prepared and analyzed scanning procedure using a $3 \mathrm{D}$ body scanner to obtain valuable and useful measurements on one side and realistic scanatars for virtual fitting on the other side.

\subsection{Sample group}

The sample group investigated comprises of 18 males $(M)$ and 32 females $(F)$ split into two ageing groups in the age of 18-39 $\left(A G_{1}\right)$ and in the age of 40-59 $\left(A G_{2}\right)$. The distribution is given in figure 3 and shows a $2 / 3-1 / 3$ splitting for the ageing groups.

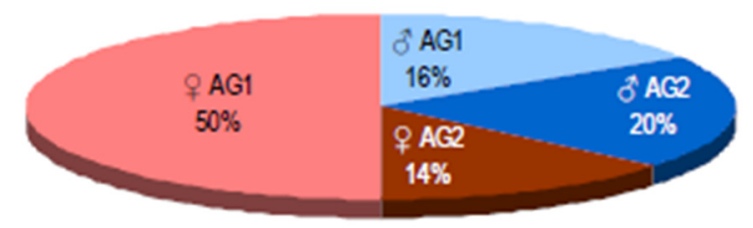

Fig. 3: Sample group distribution by age and sex 
All test subjects show a balance between the given size and the calculated BMI (body mass index) and therefore extreme body data are excluded and not part of the survey.

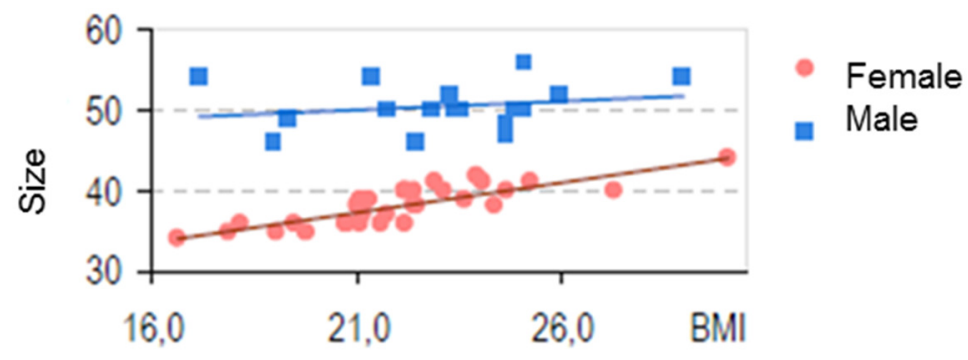

Fig. 4: Sample group classification by size and BMI

\subsection{Body scanning technology}

Scanning was done using 3D body scanning technology (ScanworX 2.9.12; Anthroscan; Human Solutions $\mathrm{GmbH}$ ) and evaluating the results by extracting measurements and overlapping the scans for visualization. Furthermore scanatars have been developed from the subjects and tested against real fittings of products. Although running all investigations with the 3D body scanner the main measurements for bust, under bust, waist and hip were always taken for each candidate and scanning position manually to control the process and if necessary to adjust the extracted scan measurement position for improving the comparison of test results. Physical markers are used to detect anatomical reference points. The classic scan and the relaxed position are also both used to generate the scanatar for the 3D simulation [4].

According to figure 5 the following 4 scans have been taken for all subjects - always strictly following the procedure without time delay (scanning number $\left.1-4 ; n_{1}-n_{2}-a_{2}-a_{1}\right)$ :

$\mathrm{n}_{1} \quad$ Scan body relaxed no tension- arms hanging down

$\mathrm{n}_{2} \quad$ Scan body relaxed no tension- arms on hip (akimbo)

$\mathrm{a}_{2} \quad$ Scan body under tension upright- arms on hip (akimbo)

$\mathrm{a}_{1} \quad$ Scan body under tension upright- arms hanging down
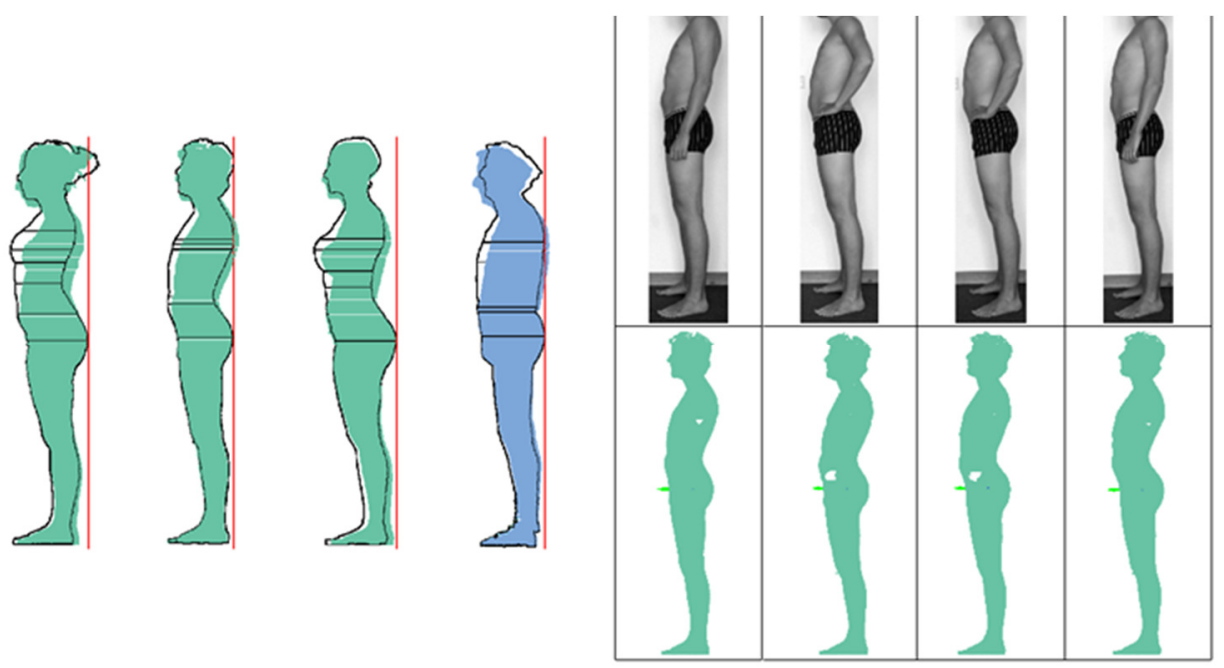

Fig. 5: Posture superposition; Posture and pose $n_{1}-n_{2}-a_{2}-a_{1}$ 
Selected subjects have undergone the following additional procedure:

Testing additional posture and pose dependent impacts:

- Standard scan position- individual relaxed position - fitting position

- Heelless, 3-5-7-10-13 cm heel

Testing physical and mental impacts:

- Dependency during the course of the day ( $9 \mathrm{am} ; 1 \mathrm{pm}, 5 \mathrm{pm}$ ) and short time (3 weeks)

- Breathing (in; out)

Testing underwear and bra dependent impacts:

- Different types of bras and bodysuits

- Different types of underwear and shape wear

\subsection{Virtual human and bodies}

Using the Humans Solutions Anthroscan Scanner and scanning software enables to generate so called scanatars using a special wizard guiding through the process [3].The scanatar is an avatar from an individual person and represents the virtual mannequin of a real person with identical body measurements and shapes. Two scan positions (scan and relaxed position) are necessary- already included in the scanning test procedure in this project. [2]

\subsection{D-simulation}

The generated scanatar files obj. from selected subjects were exported and imported to 3D CAD systems available in VirLab (Virtual product development laboratory) at Niederrhein University: Vidya assyst, CLO3D Modelist, DC Suite, 3D Prototypig Lectra, OptiTex, Vstitcher Browzwear.

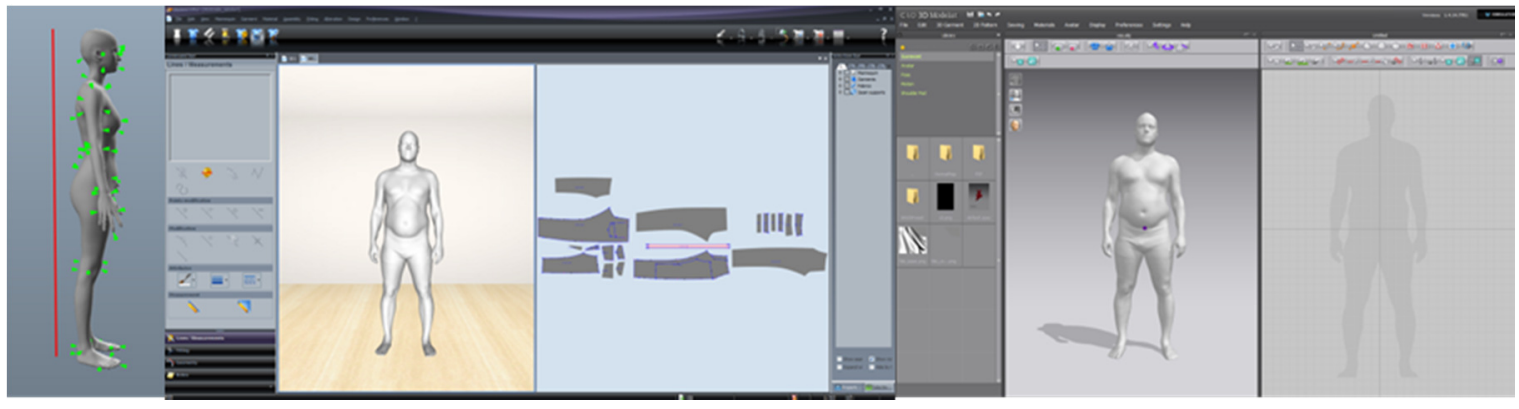

Fig. 6: Example of imported scanatars left side: $F_{7}$ imported to DC Suite center: $M_{8}$ imported to Lectra 3D Prototyping right side: $M_{8}$ imported to CLO3D Modelist

All systems offer 3D fitting tests- slightly different- with virtual sewn garments and material characteristics. Different investigation tools are implemented by detecting body distance control, pressure and tension mapping, elasticity in warp, weft and bias direction, fit.

\subsection{Products}

The products chosen for the scanning are different bras available on the market: underwire bra, sports bra, push-up bra, molded bras, suits. For the underwear especially shape wear was investigated [5]. The fitting test for the 3D virtual fitting was done by using common industry garments from selected companies for ladies outerwear and men's wear with given production patterns and materials for investigating necessarily the material characteristics. With scanatars, patterns and material characteristics the three most important parts for virtual product development are given. 


\section{Results}

The following results are extracts from the tests done with numerous females and males and the resulting fittings. They are divided up into three sections: The scanning posture and arm position impact given by two different postures and two different arm positions, the physical and mental impacts- given by the moment (breathing) or a personal body feeling of the people scanned and an underwear and bra section proving the change of body measurements depending on garment selection.

\subsection{Posture impacts}

Posture and pose dependent impacts can be controlled directly before and during the scanning process. Nevertheless the problem arises especially for the definition of the terms: relaxed, upright, fitting ...- because of individual interpretations.

\subsubsection{Scanning posture and arm position}

Scanning in different postures and with different arm positions $\left(a_{1}, a_{2}, n_{1}, n_{2}\right)$ shows subject dependent serious variations. In figure 7 the superimposed scans from subjects 15 to 35 (female and male) are presented $\left(a_{1}\right.$ and $\left.n_{2}\right)$ - upright and relaxed with arms hanging down. Whereas subject $F_{28}$ shows visible changes on upper part of the body subject $\mathrm{M}_{34}$ shows only marginal ones.

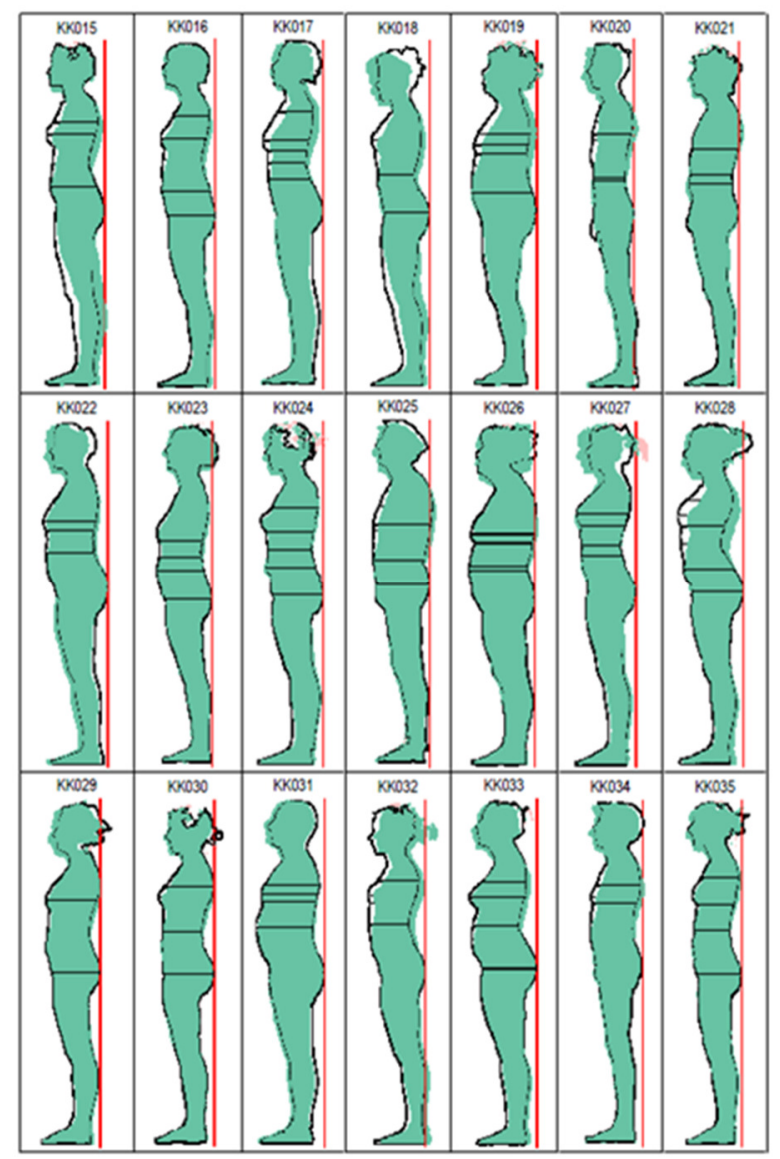

Fig. 7: Superposition of $n_{1}$ (relaxed, arms hanging down) and $a_{1}$ (upright, arms hanging down) of selected subjects

In figure 8 a detail view is given on the changes of horizontal bust and under bust circumferences measurements of subject $\mathrm{M}_{38}$.

Noteworthy is the fact that all three bust measurements (horizontal, sloped and under bust) are bigger with arms hanging down compared to arms akimbo- especially in the subject group of males.

The superimposed section planes of the horizontal bust circumference (blue line) and the under bust circumference (black line) show that the circumferences with position arms akimbo (red line) are decreasing on the back shoulder part particularly (green area). 


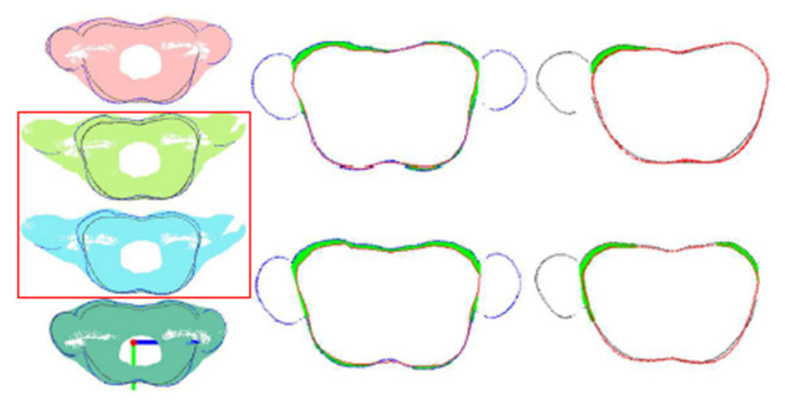

Fig. 8: Change of horizontal bust and under bust circumferences caused by different arm positions; $M_{38}$ left side: from top down $a_{1}, a_{2}, n_{2}, n_{1}$ mid: horizontal bust circumference; top $a_{1}, a_{2}$; down $n_{1}, n_{2}$ right side: under bust circumference top $a_{1}, a_{2}$; down $n_{1}, n_{2}$

In table 1 the mean of selected measurements and the calculated differences for all four scanning positions of all subjects female $\left(\mathrm{AG}_{1}\right)$ are given. Expectedly the differences between upright (a) and relaxed $(n)$ posture are much higher compared to differences given by the arm position within the same posture type. Calculating the mean simplifies the change of the bust girth horizontal measurement to $1.7 \mathrm{~cm}$ - running from $0.5 \mathrm{~cm}$ minimum to $4.3 \mathrm{~cm}$ maximum for individual subjects.

Also the front length measurement- important for women's outer garment (blouses, dresses, jackets) differs for the individual measurements from $0.9 \mathrm{~cm}$ to $4.6 \mathrm{~cm}$.

Table 1: Female $A G_{1}$; measurement differences according to scan posture and arm position

\begin{tabular}{|l|c|l|l|l|l|l|l|l|}
\hline & \multicolumn{7}{|c|}{ Body measurements [cm] } \\
\hline Posture/position & $\varnothing \mathrm{n}_{1}$ & $\varnothing \mathrm{n}_{2}$ & $\mathrm{n}_{2}-\mathrm{n}_{1}$ & $\varnothing \mathrm{a}_{2}$ & $\varnothing \mathrm{a}_{1}$ & $\mathrm{a}_{2}-\mathrm{a}_{1}$ & $\mathrm{a}_{1}-\mathrm{n}_{1}$ & $\mathrm{a}_{2}-\mathrm{n}_{2}$ \\
\hline Scan no & 1 & 2 & & 3 & 4 & & & \\
\hline body height & 165,7 & 165,2 & $-0,4$ & 166,4 & 166,9 & $-0,5$ & 1,2 & 1,2 \\
\hline bust height & 119,0 & 118,8 & $-0,3$ & 120,4 & 120,5 & $-0,1$ & 1,5 & 1,6 \\
\hline Bust girth horizontal & 92,3 & 90,7 & $-1,6$ & 92,4 & 93,9 & $-1,5$ & 1,6 & 1,7 \\
\hline underbust & 78,5 & 77,6 & $-0,9$ & 78,8 & 79,7 & $-0,9$ & 1,2 & 1,2 \\
\hline Stomach girth & 89,1 & 88,0 & $-1,1$ & 87,2 & 88,1 & $-0,9$ & $-1,0$ & $-0,8$ \\
\hline Front width & 40,6 & 41,1 & 0,5 & 45,1 & 44,9 & 0,2 & 4,3 & 4,0 \\
\hline Back width & 35,1 & 36,3 & 1,2 & 34,5 & 33,0 & 1,5 & $-2,1$ & $-1,8$ \\
\hline Back length & 37,0 & 37,1 & 0,1 & 36,6 & 36,6 & 0,0 & $-0,4$ & $-0,5$ \\
\hline Front length & 31,8 & 30,9 & $-0,9$ & 33,1 & 33,8 & $-0,7$ & 2,0 & 2,2 \\
\hline
\end{tabular}

The following diagrams show the total change of measurements (female $A G_{1}$ ) according to height, circumference, width,length and depth. It is shown that specially measurments directly linked to fit and sizing are increased in the range of the normal grading of grading tables in industry by changing from a relaxed to an upright/tensioned body posture.

Height measurements change seriously for the back height, the bust height and the neck top height. Circumference measurements change positively for the bust measurements and negatively for waist, buttocks, hip and stomach. Dpeth measurement changes show directly the displacement of body parts in the depth dorsal to ventral for upright scan positions. The front and bust length increase comes along with the decrease of the back length measurements and is critical for fit adjustments in a product development process. 
Height Measurement Changes

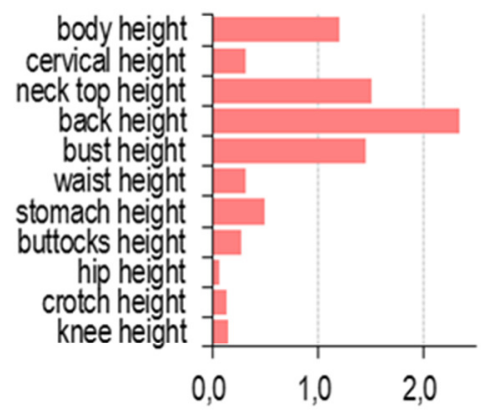

Circumference Measurements Changes

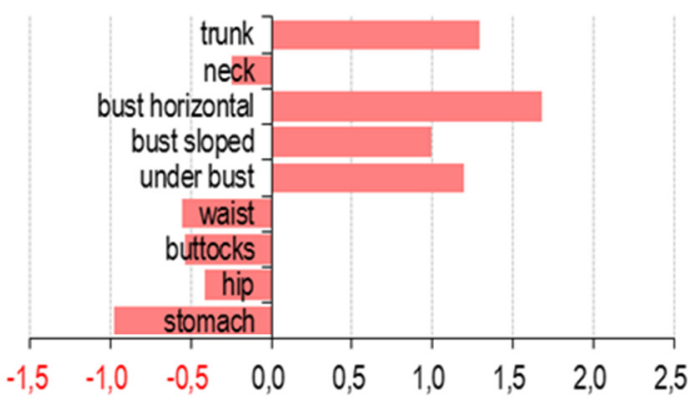

Width Measurements Changes

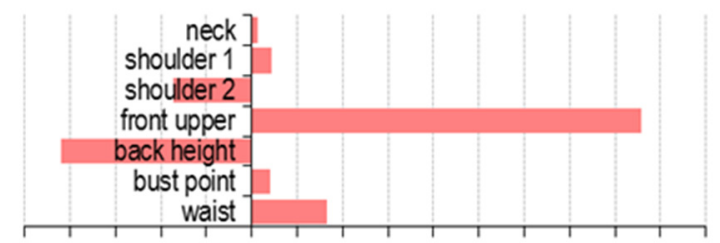

$-2,5-2,0-1,5-1,0-0,50,0 \quad 0,5 \quad 1,0 \quad 1,5 \quad 2,0 \quad 2,5 \quad 3,03,5 \quad 4,04,55,0$

Depth Measurement Changes

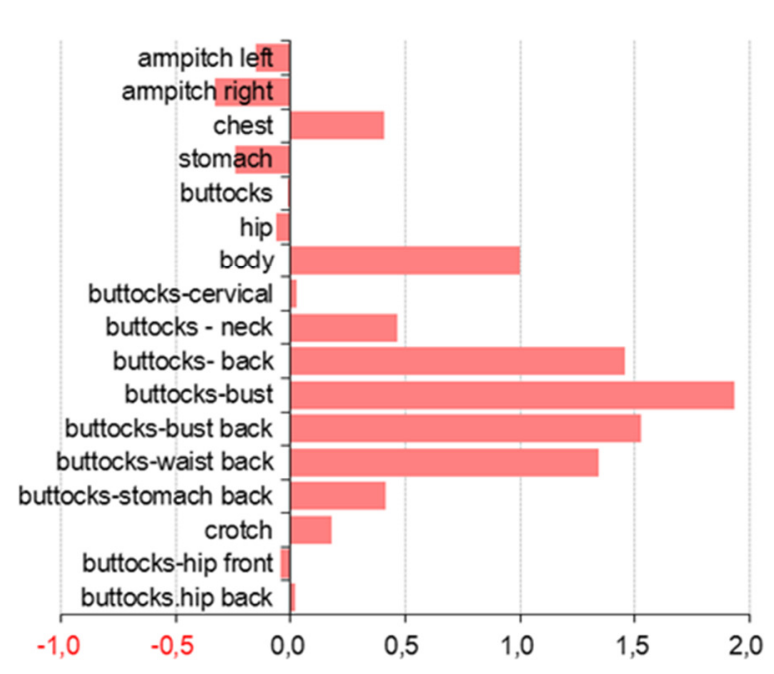

\section{Length Measurement Changes}

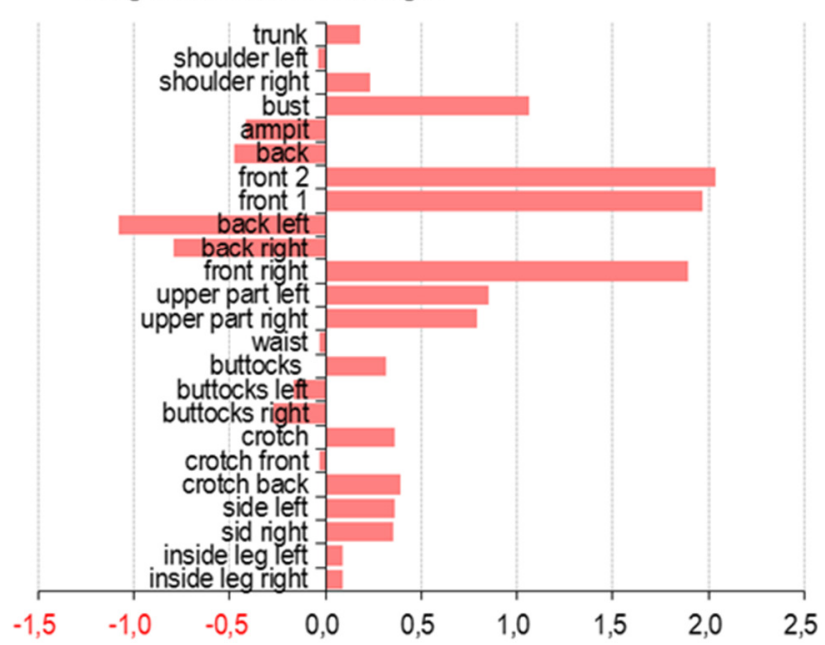

Fig. 9: Change of measurements comparing $n_{1}$ (relaxed, arms hanging down) and $a_{1}$ ( upright, arms hanging down); females $A G_{1} ; a_{1}-n_{1}$

In figure 10 an overview for both gender groups (32 females, 18 males) is given concerning the change of the bust measurement in cm-ranges for the differences between $a_{1}-n_{2}, a_{1}-n_{1}$ and $a_{2}-n_{2}$.

For more than $50 \%$ of the females a posture change from relaxed to upright comes along with an increase of the bust measurement of more than $2 \mathrm{~cm}$. For the group of males the results are even more considerable: More than $50 \%$ of the subjects show an increase of more than $4 \mathrm{~cm}$ while changing the posture.

Knowing that for most companies the bust circumference grading value is within $3-4 \mathrm{~cm}$ the meaning of posture dependency for fitting and especially virtual fitting tests is given. 


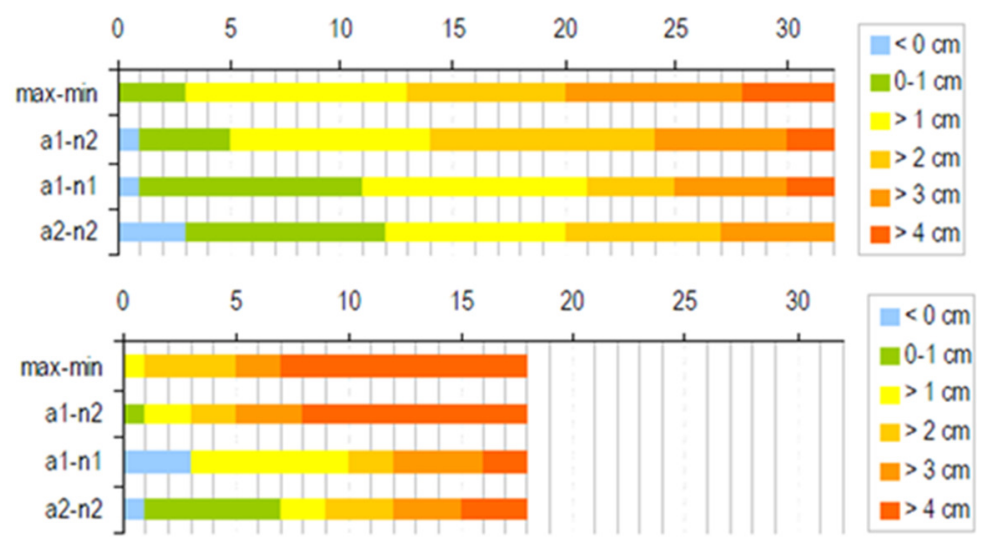

Fig. 10: bust measurement differences for 32 females (top) and 18 males (bottom)

\subsubsection{Heel dependency}

Fig.11 shows the scanning result and the extracted measurements of Female $F_{2}$ in two different postures: heelless and with high heels of $13 \mathrm{~cm}$. Obviously only the change of the posture increase the chest girth with $2.4 \mathrm{~cm}$. Other results show measurement alteration in the range of grading values by changing the posture.

a)

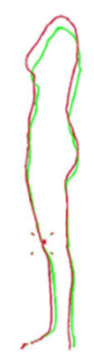

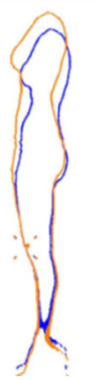

b)

\begin{tabular}{|l|c|c|c|c|c|c|}
\hline & \multicolumn{5}{|c|}{ Body measurements [cm; $\left.{ }^{\circ}\right]$} \\
\hline Heel position & \multicolumn{3}{|c|}{ heelless } & \multicolumn{3}{c|}{ heel $13 \mathrm{~cm}$} \\
\hline Posture/position & $\mathrm{a}_{1}$ & $\mathrm{n}_{1}$ & $\mathrm{a}_{1}-\mathrm{n}_{1}$ & $\mathrm{a}_{1}$ & $\mathrm{n}_{1}$ & $\mathrm{a}_{1}-\mathrm{n}_{1}$ \\
\hline Bust/chest horizontal & 90,2 & 87,8 & 2,4 & 88,8 & 88,1 & 0,7 \\
\hline waist & 71,3 & 71,8 & $-0,5$ & 73,2 & 72,1 & 1,1 \\
\hline hip & 101,3 & 101,4 & $-0,1$ & 102,9 & 103,2 & $-0,3$ \\
\hline shoulder angle left & 27,8 & 30,3 & $-2,5$ & 26,4 & 29,2 & $-2,8$ \\
\hline shoulder angle right & 27,3 & 29,1 & $-1,8$ & 25,6 & 29,4 & $-3,8$ \\
\hline
\end{tabular}

Fig. 11: a) Scan superposition $a_{1}, n_{1}$; heelless, $F_{2}$

b) Scan superposition $a_{1}, n_{1}$; heel $13 \mathrm{~cm}, F_{2}$

In Fig. 12 a simple skirt balance dependency is shown by changing the position $\mathrm{n}_{1}$ (relaxed, arms hanging down) from heelless up to 7 and $13 \mathrm{~cm}$ respectively.

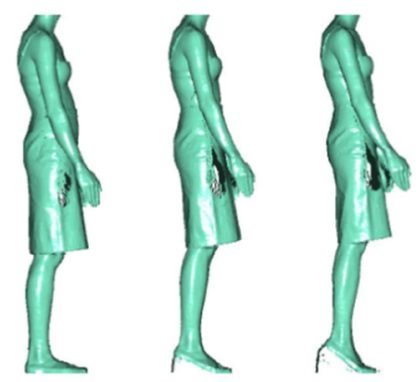

Fig. 12: Skirt balance dependency; subject $F_{1}$ heelless- heel $7 \mathrm{~cm}-$ heel $13 \mathrm{~cm} ; F_{4}$ 


\subsubsection{Relaxed and fitting position}

Figure 13 shows the results of a virtual fitting for a basic blouse (normal fit) German size 38 and the problems resulting from two different scanning positions: On the left side scanning was done in a more or less relaxed scanning posture with arms hanging down- on the right side the same procedure for generating the scanatar was followed but using a scan from a more upright position also with arms hanging down was taken. The bust circumference has increased with notable $3.7 \mathrm{~cm}$ for the upright posture and effects seriously the fit of the garment- the blouse fits now too tight on the bust and shows unwanted fullness on the back part. As in reality and shown in the chapters before posture and position have a huge impact on body measurements: Whereas in reality posture and position can be changed quickly the generation of a certain range of scanatars has to be well prepared.
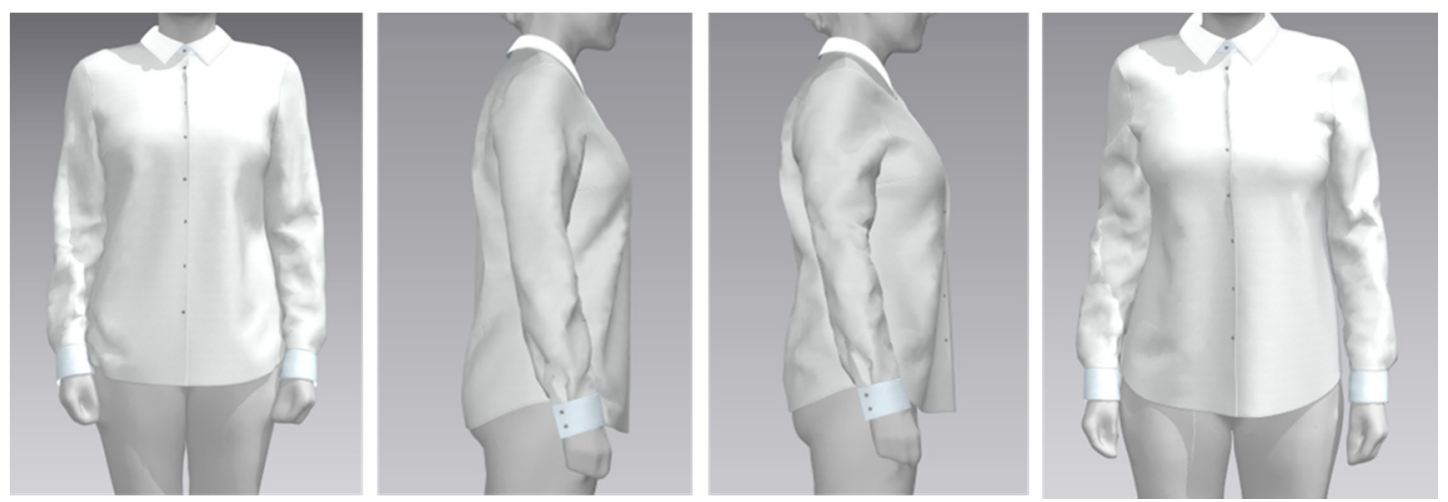

Fig. 13: virtual fitting basic blouse - $F_{49}, C L O 3 D M o d e l i s t$ left side: scanning position $n_{1}$, relaxed no tension, arms hanging down right side: scanning position $a_{1}$, upright body under tension, arms hanging down

\subsection{Physical and mental impacts}

Physical and mental impacts are difficult to control and depend on one side from the form of the day and eating habits/personal diet and on the other side from mental conditions. Scanning subjects for virtual fittings in an innovative product development process is therefore a challenge and leads to the fact that multiple scans should be taken.

\subsubsection{Daytime and short time dependency}

In figure 14 the circumference measurements of subject $F_{12}$ are shown over a period of 3 weeks with scanning done Monday to Friday at $9 \mathrm{am}, 1 \mathrm{pm}$ and $5 \mathrm{pm}$. Properties for underwear and bra have been kept constant.

All 5 measurements are kept in a certain corridor- varying over daytime and from day to day.

Bust, waist and buttocks range up to $5 \mathrm{~cm}$ whereas under bust up to $4 \mathrm{~cm}$ and hip up to $2,5 \mathrm{~cm}$. Again the grading values according to industry charts are reached.

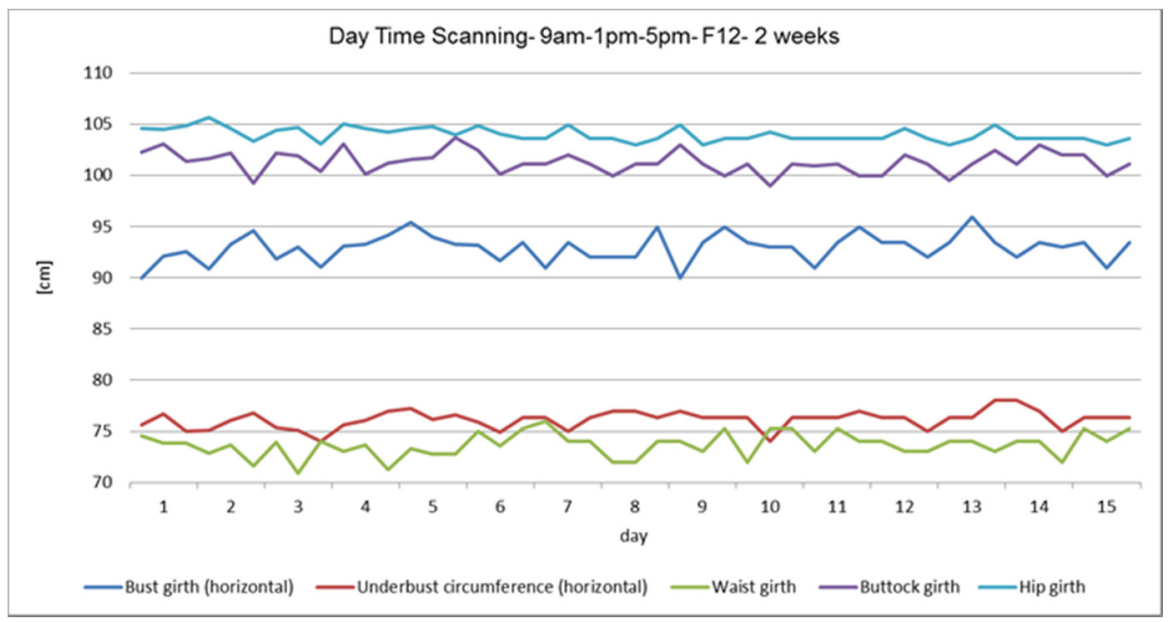

Fig. 14: Short time dependency- day time scanning 3 weeks; $F_{12}$ 


\subsubsection{Breathing dependency}

Breathing changes subject dependent the bust measurements according to the lung volume change and the stomach measurement when breathing in.

In figure 15 three different breathing types of Male $M_{6}$ are shown: normal breathing, bust breathing and abdominal breathing- normally done and not excessively.

For a more accented bust breathing the horizontal bust measurement increases $1 \mathrm{~cm}$ and decrease 1 $\mathrm{cm}$ for abdominal breathing. The stomach measurement $(105 \mathrm{~cm}$ from ground) shows a plus of $2.1 \mathrm{~cm}$ for the abdominal breathing.

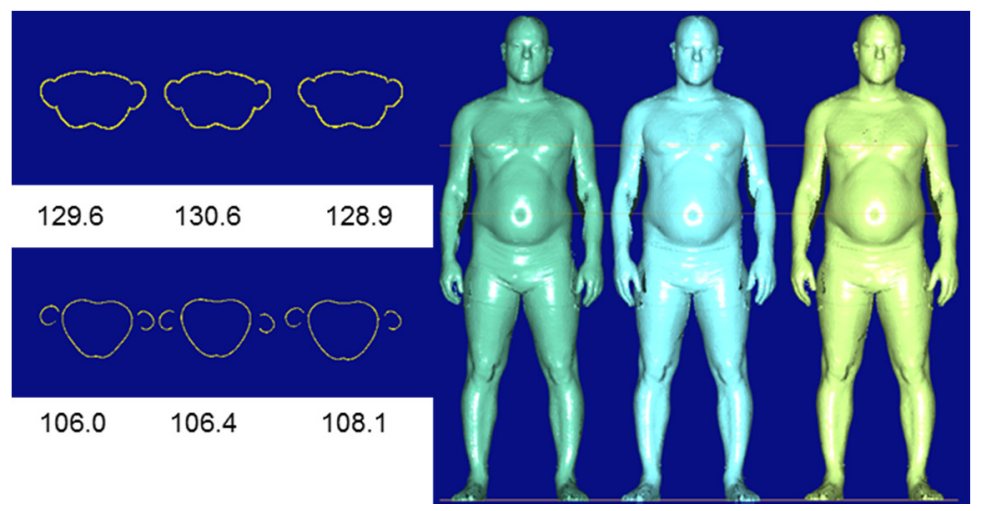

Fig. 15: Breathing dependency; Ms' Measurement circumference plane 105, $130 \mathrm{~cm}$ left side: normal breathing center: bust breathing right side: abdominal breathing

\subsection{Underwear and bra dependent impacts}

Underwear and bra are garments which may influence female body dimensions and therefore fit accordingly. For real fitting sessions and also virtual fitting sessions the influence should be checked to control the design and pattern making process and if necessary do amendments.

With regard to a target group more or less unknown also the real parameters are not detectable but necessary to be aware of to achieve an optimum of fit according to target sizing.

\subsubsection{Underwear - shape wear dependency}

The influence of underwear is mainly dependent from the compression effect of the garments and shapes hip, thigh and buttocks area.

Also without knowledge of a special compression effect implemented- so called shape wear- similar effects can be achieved by wearing to tight fitted underwear- strongly depending on the material used. The fit of tight fitted skirts, dresses and trousers can drastically be changed by implementing consciously or unconsciously a compression effect.

\subsubsection{Bra dependency}

For the upper part of female bodies the bust is the most important measurement and therefore investigated in detail. Mostly bras, tops and bustiers and basques are worn with straight effect on the bust measurements in circumferences and on position especially bust point position.

In table 2 the change of measurements are given for female $F_{5}$ scanned with different bra constructions, tops and bustier in scanning position $\mathrm{n}_{1}$ (relaxed, arms hanging down) The effect is a mixture and superposition of compression and displacement with a compression effect of more than 5 $\mathrm{cm}$ and displacement of $\sim 2 \mathrm{~cm}$ of bust point- which can be even stronger for other textile constructions.

As shown by the results the terms given for the bra types are not always corresponding to the properties usually expected- depending on sizing, individual body shapes and age of females.

The bust point displacement of up to $2 \mathrm{~cm}$ is already critical for tight fitted ladies wear with bust dart running in straight direction to the bust point. 
Table2: Measurements according to bra type; $F_{5}$

\begin{tabular}{|l|l|l|l|l|l|l|}
\hline & \multicolumn{5}{|c|}{ Body Measurements [cm] } \\
\hline Product & Top & Bustier & $\begin{array}{l}\text { Sport } \\
\text { bra }\end{array}$ & $\begin{array}{l}\text { Bra } \\
\text { unlined 1 }\end{array}$ & $\begin{array}{l}\text { Bra } \\
\text { unlined 2 }\end{array}$ & $\begin{array}{l}\text { Push up } \\
\text { bra }\end{array}$ \\
\hline Across front width & 41.9 & 43.8 & 43.2 & 40.5 & 43.0 & 42.8 \\
\hline Neck right to waist over bust & 50.7 & 54.9 & 50.8 & 53.1 & 52.5 & 53.2 \\
\hline Bust point to neck left & 32.6 & 32.0 & 31.2 & 31.5 & 30.5 & 31.5 \\
\hline Bust point to neck right & 32.9 & 32.6 & 31.8 & 32.3 & 31.8 & 31.9 \\
\hline Bust/chest girth (horizontal) & 110.0 & 109.1 & 109.8 & 112.6 & 113.5 & 113.2 \\
\hline Bust/chest girth sloped & 109.6 & 108.2 & 107.9 & 111.3 & 112.3 & 110.6 \\
\hline Underbust circumference & 96.0 & 93.8 & 91.7 & 91.6 & 93.7 & 90.2 \\
\hline Waist girth & 85.4 & 88.5 & 82.6 & 81.4 & 81.2 & 81.6 \\
\hline
\end{tabular}

\section{Discussion and Conclusion}

The results in this paper have proven the importance of posture and position selection in 3D body scanning procedures for generating body measurements and specially the impact on virtual fittings by using so called scanatars produced by. Knowing that not all parameters can be fully controlled and few of them are changing hourly, most of them can be fixed and measurement extraction and scanatars are delivering valuable data. Therefore posture and position have a big impact on the results but can be controlled during the scanning process and offer additional information. Physical and mental impacts are hardly to control but facilitates on the other side a realistic view.

Whereas on one side the danger of getting unrealistic measurements, scanatars and fitting results is given by an undefined quick scanning process the possibilities offered are immense: Fitting models and subjects representing more or less the target group of the company can be scanned in various postures, positions and additionally individual parameters can be checked and a broad range of scanatars is created for the virtual fitting. The broad range of scanatars (e.g. same measurements but different body postures or measurement distribution-bust front, armhole scye- back width) offers the possibility of checking quickly the fit and working on optimum solutions- keeping in mind that the industrial product development is usually not a tailor made process or reduced to few mannequins not really representing the target group.

\section{References}

[1] S. Ashdown: "Sizing in Clothing", Woodhead Publishing, April 2007.

[2] M. Ernst: "Pattern Makers Guide Through Virtual Media", IACDE World Conference, Heidelberg, Germany, May 5, 2014.

[3] M. Ernst: "3D CAD- A Teaching and Lecturing Challenge", 5th Lectra International Education Congress, Milano, Italy, 07-08 November 2013.

[4] M. Ernst: "Innovative Product Development", Tswhane University of Technology, Pretoria, Fashion Technology Department, Pretoria, South Africa, August 14, 2012.

[5] M. Ernst and U. Detering-Koll:"Investigation on Body shaping Structures Using Body Scanning Technology and 3D Simulation Tools", in Proc. of $3^{\text {nd }}$ International Conference on 3D Body Scanning Technologies, Lugano, Switzerland, 16-17 October 2012.

[6] S. Molcho: „Alles über Körpersprache“, Sonderausgabe. München: Mosaik, 2001.

[7] R. Trieb: „EUROFIT-Integration, Homogenisation and Extension of the Scope of Large 3D Anthropometric Data Pools for Product Development", in in Proc. of 4nd International Conference on 3D Body Scanning Technologies, Long Beach CA, USA, 19-20 November 2013.

[8] H. Voss and R. Herrlinger: „Taschenbuch der Anatomie“, Band 1: Einführung in die AnatomieBewegungsapparat. 15. Auflage. Jena: VEB Gustav Fischer Verlag, 1957.

[9] ISO 8559, (1989): ISO International Standard on "Garment construction and anthropometric surveys-Body dimensions".

[10] ISO 7250-1, (2008). "Basic human body measurements for technological design" - Part 1: Body measurement definitions and landmarks. 